cate of it, a skilful surgeon, Dr. Estes, ${ }^{3}$ of Pennsylvania: "After a transverse fracture has been thoroughly reduced and the fragments accurately adjusted, there is comparatively little danger of the fragments slipping, if the foot be kept quiet and some stiffening splint be applied to the leg. Plaster-of-paris splints I have found ideal in these cases. Two strips of tin, one on either side, or some flexible wood splints may be used as apposition splints at the seat of fracture, to prevent any movement of the fragments, until the plaster hardens. Before applying the plaster it will be well to pad the leg with an even layer of cotton-wool and to use a Hlannel bandage over the cotton, neatly, but not too tightly, applied, from the toes to the knees. If the fracture be near the knee it will be well to extend the plaster dressing 6 inches above the knee. . More or less swelling will surely result after fractures of the bones of the legs; it is well, therefore, to bear this in mind and never use very tight bandages. 'The cotton-wool when properly used and the bandage skilfully applied will prevent any hurtful pressure resulting, but the surgeon should carefully watch the extremity for twelve lrours after applying the dressing, and he should instruct the patient and his attendants to notify him at once in case great pain in the extremity or swelling and discoloration of the toes should take place. In any case which it will be impracticable for the surgeon to see within ten hours after the application of the plaster-ofparis dressing, he should insert, while applying the dressing: a narrow strip of tin under the plaster just over the flannel bandage, and instruct the attendants in case swelling and persistent and very severe pain should follow, at once to cut through the bandage upon the tin strips with a penknife, and so loosen the dressing."

The necessity of splinting having been shown and the plaster-of-paris treatment described, it remains to consider, in the third place, the new leg-splint.

\section{THE NEW LEG-SPLINT.}

After the fracture is reduced, a piece of wood-plastic material is suitably cut, moistened with water and bandaged snugly upon the limb, directly next the skin, so that it embraces the shin-bone. The middle line of the long axis of the splint coincides with the anterior border of the tibia. This splint, lying next the skin, gives an efficient immobilization. It is light, cheap, and durable. At any time the surgeon can inspect the bone by unwinding the bandage and lifting up the splint. It thus permits of massage, to the importance of which this paper has already referred. There are no bits of wood, nor tin strips to be kept in place, no cotton batting to impair fixation, no flannel bandage, and no mussy application of plaster-of-paris.

Should the loosening of the apparatus be required in the absence of the surgeon, it can be done by simply unwinding the bandage. It is no easy matter for one unfamiliar with the technique to remove a plaster-ofparis "cast." The writer has treated cases of fracture where he would as well expect the attendant to know how to do an amputation, as to remove a plaster-of-paris dressing from a broken limb.

In conclusion, it is claimed that the leg-splint described fulfils the requirements deemed essential in the treatment of a broken bone, namely, efficient fixation, easy removal for inspection, or the application of massage, and proper protection of the weakened limb until normal bone reunion is complete.
SOML UBSERVATIONS IN RENAL SURGERY.:

IV. H. ALLPORT, M.D.

SCRIEON TO ST. LCKE'S HOSPITAL.

CIIICAGO.

'This paper is a contribution to the natural history of error. In these days of entliusiastic renal surgery every frank analysis of diagnosis gone wrong, of operative blunders committed, of difficulties unexpectedly faced, must be not only of interest but of actual value to those undertaking operations on the kidney. It is a trite enough observation that we learn more from defeat than from victory-this is my apology for directing attention to certain of the errors observed during the development of the cases recorded in this article.

Jacobson describes nephrolithotomy as "one of those advances in modern surgery in which the operation has outstripped the diagnosis." 1 This statement is borne out by the astonishing fact that of twenty-seven nephrotomies for stone he met failure in six. Henry Morris also remarks that within his observation sixteen unsuccessful explorations of the kidney had occurred. 'Those who are overconfident of their own abilities, or disposed to think harshly of diagnostic error in others, would do well to study carefully the valuable outlines furnished by Jacobson of his six unsuccessful cases. ${ }^{2}$

It is a pity that this classification of error has not been extended further, so that we could have some statistical view of the percentage of miscarriages occurring in all kidney undertakings in the practice of some of the best diagnosticians and operators. For it would appear that the true terra incognita of present day surgical investigation lies behind rather than within the abdominal cavity. It is instructive to observe that this lack of definition as to the exact location and condition of the kidneys, which has not yet been sublimated out of the medical mind, is reflected on lines of broader ignorance in the sensorium of the layman, who never displaces heart or liver, rarely has left-sided appendicitis, yet incorrigibly locates his urinary organs anywhere from the sacrum to the vertebra prominens and from the spinous processes to the axillary line.

The cause for this constantly recurring inexactitude of place conception becomes on consideration sufficiently apparent, nor can it from the nature of things ever be thoroughly eradicated even from the medical mind, but must continue forever as a bar to anything better than a respectable percentage of perfect diagnosis. Our direct ideas of location and condition or quality of any organ or thing are based on sense perceptions, which enable us to separate it from other structures and conditions; bearing this fact in mind, it becomes immediately obvious that we can predicate little-with that certainty which we apply to ordinary things-of an organ which can never be apprehended by sight or touch except as disguised by the body wall, and is never directly or indirectly manifest to the other three senses. Moreover, while the absolutely definitive location of a kidney as such becomes singularly elusive, much more so must be the definition of local and limited disease within the organ itself. It must, indeed, be admitted that we are rarely in a position where the surgeon can predicate with certainty and from direct testimony the complete location and condition of any given kidney before exploration.

What I have said with reference to the uncertainty of the direct evidence of position and structure, applies with equal truth also to any indirect or circumstantial 
methods employed to fasten the diagnosis of surgical disease upon one or both kidneys. It is an axiom of logic that the number and limitation of the premises being indefinite, the deductions must perforce become uncertain. Nowhere does this truth obtrude itself more constantly than during the endeavor to formulate a consistent and ultimately correct theory concerning an organ, the exact duplicate of which is found on the opposite side of the body, both organs pouring their only evidence of activity and identity into a common receptacle, and both of which are buried in fat and muscle and surrounded on all sides by organs, themselves scantily perceptible and themselves perhaps pathological both in location, position and intimate structure. Here we must of necessity often lodge finally, if we are honest, in a mere probability, putting up the moment before the incision with "the most likely looking" diagnosis, and more or less contented to follow in the lead of Lawson 'Tait, who solved the same kind of operative difficulties by observing laconically that "the kidney is best reached by the most likely-looking road."

Again, in groping for safe and infallible guides to this diseased organ, the surgeon is many times tempted to make deductions from single classical relations assumed on too narrow grounds to be inflexible in spite of changes in other organs and relations. If we would not make the error of placing the normal where it becomes abnormal, we must admit that normal relations disappear with the development of diseased conditions, so that no relation can be said to be normal or to be counted on in the presence of pathology. Most of us have at times lost sight of the fact that the principles of regional anatomy can not be applied to organs which have become so distorted through disease as to fall entirely out of their position, leaving vacancies into which other organs are at liberty to fall. We must admit that the colon lies in front of the kidney, and that the spleen and liver and gall-bladder lie above and in front of the colon; yet if we apply these truths too liberally, or lay down too many rules for the surgical guidance of our country friends, based on the literal and normal anatomy of these parts, we land them presently farther from the truth than if they had attacked their problems with ordinary common sense. Certain of the cases cited below bear witness to this point.

A somewhat acrimonious discussion which took place two years ago as to the relations of the portal vein to the common duct of the liver served to illustrate the fact that normal relations may be dangerous to follow in pathological and surgical dissections, for while we must admit that the vein normally lies entirely behind the duct, many of us have had occasion to thank Dr. C. Fenger for calling attention to the fact that in the engorged and distended portal vein incident to many diseases of the liver, the duct may be imbedded in and surrounded, in a great measure, by the vein.

This paper, therefore, is not written with the idea of exploiting any new or peculiar method of diagnosis in renal surgery, but rather to show that after careful consideration of this class of cases, and after applying faithfully to the elucidation of their diagnosis all of the methods commonly noted in the text-books, we still find it necessary many times either to confess ignorance or to run a large chance of being presently overtaken by error.

In the following reports we see the kidney taken for the spleen, and the spleen for the kidney; we see the liver sinking behind the colon to confound the surgeon in search of a kidney, and the kidney stretching its pedi- cle until it lies flush against the anterior abdominal wall; we see the gall-bladder finding its way into the loin and again into the iliac fossa, perinephritic abscess masquerades as calculus or appendicitis, and empyema as renal cancer. We see stone in the kidney treated for Bright's disease by the clinician, but we also see the kidney cut by the surgeon for stone and none found. Surely a chronicle such as this must give us pause if too much inclined to assume the skiagraphic eye when making a diagnosis of those surgical diseases lying in relation to the posterior reflection of the peritoneum.

CASE 1.-A. B., aged $2 i$, country schoolmaster by profession, of good family history, but of excessively neurotic temperament, came to Cook County Hospital, complaining of frequent and painful micturition, with pains shooting into both groins from the lumbar region.

There was no history of gonorrhea, or of sexual indulgence of any kind, no varicocele, and the patient was unmarried. There could be no question about the frequency of the micturition, which occurred at least every half-hour during both day and night, and had caused him to lose much flesh through loss of sleep and food. An examination of the urine showed hyperacidity, a few biood cells, but no pus. An exploration of the bladder by means of the sound revealed nothing except an abnormally sensitive prostatic urethra, which was accordingly dilated, but without improvenont. After trying various remedies, including large doses of bromids and pichi, the patient begged for operative measures, and accordingly the bladder was opened and drained, with complete relief of the symptoms. This relief, however, continued only as long as the bladder was open, and when the wound closed-which it did sume time after his return home-his symptoms were as bad as ever, and he was absolutely unable to perform any of his duties. He returned to the hospital, where he showed no change in his symptoms, except that the pain was referred more directly to the left side. He underwent a nephrotomy of that kidney, the organ being thoroughly explored for stone or other pathological con. dition, but nothing abnormal was found. After this operation he was assured that he would be absolutely relieved, which proved to be the case until sone time after he returned hone? and the wound was thoroughly healed. Eventually, his symp. toms returned, this tine being referred to the right kidney witl redoubled severity, and he came once more to the hospital, very much emaciated and begging for a final operation on the remaining kidney. At this time his symptoms were thoroughly canvassed; the acid urine voided at frequent intervals and con taining blood in small quantities, together with the pain shoot ing from the loin into the testicles, were thought to justify a third search for stone. At the third operation the result was similarly negative, except that there was an obstinate hemorwhage, which was thought at the iime to have been controller by gauze packing; during the night there was either a contin uance or a return of the hemorrbage, and the patient died At the post-mortem, there was found an incision into the renal vein, from which something like two quarts of blood liad escaped, finally forcing its way into the peritoneal cavily. Other than this, there were no conditions which could be called pathological beyond great thickening of the bladder wall with an abnormally small bladder. There was no stone.

This painfully instructive case discloses the fact that frequent and painful micturition with acid urine and a mild hematuria, may result simply from abnormally developed excitability of the genitourinary system, produced by conditions closely resembling hysteria. In the absence of better defined objective symptoms of organic disease it would seem that this case should never have come to an operation. Nature, unhampered by the suggestion of operative interference would very likely have worked out a cure.

CASE 2:-G. S., age 32, normal weight 210 pounds, saloonkeeper by occupation, was referied to a hospital with what was thought to be appendicitis requiring operation. After some days treatment in the hospital under observation both of the 
physieian and the surgeon, his symptoms subsided, and the case not seeming to call for an immediate operation, he was discharged, under the diagnosis of catarrhal appendicitis.

After leaving the hospital, the patient returned to his occupation, but continuing to lose flesh, his weight then being aboui 190 pounds, he consulted several surgeons for the purpose of confirming or establishing a diagnosis. By one surgeon his condition was held to be due to appendiceal abscess, with the appendix lying underneath and parallel to the colon; by another, a diagnosis of renal calculus was made. He then consulted the writer, and after an examination of the urine, which was neutral and contained a small quantity of blood and pus, I held to the first diagnosis, believing that the organic elements in the urine were due to the proximity of the abscess, the large number of the symptoms, viz., pain, slight temperature, constipation, recurrent intestinal colic, with occasional vomiting attacks being thought sufficient to turn the diagnosis in the direction of appendicitis. There was no tumor, but the right rectus abdominis was rigid and deep pressure showed tenderness. At the operation I found the appendix non-adherent and non. suppurating, but erect and in a condition of catarrhal inflammation. It was therefore removed, and the wound healed without temperature or complication. Shortly before leaving the hospital, the urine commenced to show a considerable increase in the quantity of pus, the reaction varying from mildly acid to mildly alkaline, and an evening temperature of $100 \mathrm{de}$ veloped. This was thought to be due to a chronic cystitis, the patient having drank the alkaline Missouri River water for several years. A deep stricture was found and dilated, and the bladder washed out daily. The temperature fell, and most of the pus disappearing from the urine, he was discharged feeling much improved. After a period of about three months the patient returned with a farther loss of weight of about twentyfive pounds, stating that the pain in his side, which appeared to have been relieved by the operation, had returned, together with hectic fever and a large quantity of pus in a neutral urine, accompanied by intermittent hematuria. It then becamo evident that the diagnosis of stone in the kidney was a most probable one, since there was great and definitely located pain on pressure below the twelfth rib, which could not be said to have existed as definitely before. The pelvis of the kidney was therefore opened and drained. No stone was found, although the needle was freely used in exploring the kidney substance, but the pelvis on exploration was found to contain a considerable quantity of pus, blood and debris. This was thought to represent the extent of the disease. The operation was followed by fall of temperature, and cessation of the symptoms, except the pyuria continued, though less in quantity. The tube remained in the wound for three weeks, and the patient was discharged with a urinary fistula, through which at least a poition of the urine of that kidney made its escape. It was thought that a subsequent nephrotomy would be necessary at no distant date. In two months my good friend returned, emaciated by hectic fever and pain to 140 pounds, and with the urine containing a large amount of pus, but no tubercle bacilli or cheesy particles. At the third operation, which was purformed under great difficulties in consequence of the enormuus development of fibrous tissue in and around the kidney capsule, at least one-half of the renal structure was found to have disappeared, being replaced by fibrous and granulation tissue and sinuses leading in several directions. No abscess, however, was seen until the kidney had been partially extirpated and drawn into the wound. This procedure was attended by increasing difficulties, owing to the adhesions in all directions requiring a dangerous amount of traction to deliver the organ and its capsule. These adhesions were especially noticeable in a direction upward and behind the Iiver, and the final effort to free the organ literally pulled out the wall of a large cavity above the kidney and between the liver and diaphragm. After such pedicle as was possible had been formed from the fibrous tissue adjacent to the pelvis, the pedicle was clamped with three large forceps, which were left in situ, it being impossible to differentiate the ureter and renal vessels in the mass of adhesions. Attention was then directed to the abscess cavity, from which was cleared out a great quantity of pus, broken- down blood-clot, granulation tissue and partly organized abseess wall. In evacuating this mass of semi-solid debris, my entire hand was introduced between the liver and the diaphragm, barely reaching to the top of the cavity, but not identifying disease either of the lung, liver or spine as the source of the suppuration. The operation was followed by no shock, the fever and pain at once disappeared, and within a week the urine was free from pus. The clamps were removed on the third day and there was no resulting hemorrhage. It was found, however, that a small portion of the kidney had been left in the lower portion of the wound, and from this urine continued to be secreted through a sinus for about two months. 11ert were no other complications, and at the end of three weeks tite patient left the hospital. In three months the wounu wa, entirely healed, and the patient at the present time weighs 230 pounds, secretes a normal quantity of normal urine, and is indulging enormously in stimulants.

It is of interest to know that this patient, when about to leave the hospital for the fourth time, finally recollected having fallen heavily against some article of furniture while entering his house one night in an intoxicated condition, and that he spent two days in bed, suffering great pain in the right lower portion of his chest, and that there was some discoloration of the skin over the lower ribs, continuing until about six weeks before he went the first time to the hospital.

This case certainly illustrates to a remarkable degree the vicissitudes of renal surgery. In the light of subsequent developments, some of the errors may seem inexcusable; nevertheless, I was not the only one who fell into them, for two other surgeons had previously made a diagnosis of appendicitis as the pathological condition. It is obvious that the error was based on too little attention paid to the relation of the pain to $\mathrm{Mc}$ Burney's point, and in failing to give the small amount of blood and pus present from the first in the urine their proper value. The temporary improvement in the patient's condition after the first two operations was due to the rest in bed. Again, it is probable that not sufficient care was taken in securing a previous history and a little more careful questioning by his four or five surgeons might have brought out the story of trauma. Too little attention also was paid to the fact that the urine was often acid in reaction, although containing pus and blood; this would have ruled out the theory of cystitis secondary either to stricture or to the drinking of alkali water. Fourthly, the first operation on the kidney should have been a nephrectomy and not a nephrotomy, thus saving the patient the perils of three operations. Lastly, the questions must arise, Was this abscess primarily in or above the kidney, and by what method could it have been located in the absence of bulging of the side and increased liver dullness?

CASE 3.-Mrs. B., came to me with the diagnosis of Bright's disease, having been under treatment for one year for chronic nephritis. I found her suffering with slight temperature, and there was great pain in the right lumbar region shooting into the groin; there was a point of greatest tenderness about two inches above the anterior superior iliac spine, not accompanied by swelling. The urine was acid, contained no casts, but a large quantity of blood, pus and mucus; after filtration there was no more albuminuria than the blood serum would account for, and after repeated examinations, most of the blood, with practically all of the albumin disappeared. She was presently sent to the hospital for a nephrolithotomy, but prior to going there two skiagraphs were taken, the lower end of the plates reaching to the crest of the ilium. On development these proved negative, and the operation was postponed for several days until the urine could be taken from the separate kidneys after Harris' method. The separate urine analyses also proved negative, for the urine from both kidneys was acid, 
and contained pus and few blood cells. On account of these negative findings, the operation was again deferred, the patient was put on large quantities of water with urotropin, and the bladder was washed out daily.

Under this treatment she steadily improved, and as there was no recurrence of the pain she was discharged from the hospital and visited me at my office. She gained in weight and comfort for two months, and one day brought in a brownish calculus the size of a navy bean, which had passed without pain. On examination the calculus was found to be rough, but nearly round, and to consist almost entirely of urates. She is now in good health, though pale, and the urine still contains pus and mucus, but no blood.

This case is a typical one of nephrolithiasis, but the negative character both of the skiagraph and the analysis of the separate urines saved the patient from an operation. Had the pain continued, or should it have recurred the indication was clear for operation, but it is plain that neither skiagraph nor separate urine analysis gave any assistance in diagnosing. It is possible, however, that the stone was in the ureter below the field of the plate:

CAse 4.--Mrs. $H$. In this ease a very small stone was im. bedded in the right kidney of a stout, gouty woman. Pain, accompanied by the passage of very small particles of gravel, without hematuria, were the only symptoms. The urine was acid, and contained urates. I hesitated to operate until a skiagraph had been taken, which showed a small stone on the right side. At this operation I had occasion to experience the solid comfort which can come from the positive evidence of the shadow found in the skiagraph, for without the testimony of the picture the search for the stone would have been abandoned. On opening the pelvis nothing abnormal was found, and the needle was introduced over twenty times before it encountered a small uric acid calculus the size of a split pea deeply imbedded in the substance of one of the pyramids. The operation was followed by a complete recovery from the symptoms.

CASE 5.-Mrs. B. A case where phosphatic gravel was repeatedly passed, together with blood and pus, and with intense pain located in the left loin. A sound in the bladder found numerous rough, gravelly surfaces and some ulceration. The surfaces were gently curetted and the bladder washed out daily, but there was no relief from the pain, which apparently radiated from the left kidney. No skiagraph was taken, as the symptoms were thought to point sufficiently toward stone in the kidney to warrant a nephrotomy. This was performed without result, the pelvis being thoroughly explored, and the kidney, which seemed perfectly healthy, was repeatedly needled. The wound closed rapidly, with no apparent infection, and the patient was sent home. In four weeks she returned with high fever, chills, and great pain in the same kidney, which was thereupon opened and found to contain multiple abscesses, requiring a nephrectomy, which was performed by Dr. Eisendrath. The wound did well, with the exception of a sinus from the ureter, and six weeks later I dissected out this structure from the kidney incision down to the broad ligament. She then made a good recovery, but still continues to sufier wit. her bladder, the condition of which seems to be due to a cystocele.

It would appear that this nephrotomy should hardly have been performed wihtout a previous skiagraph, especially since the patient was hysterical and complained of pain in the opposite side. I am also convinced that while the case has been previously reported ${ }^{3}$ as one of surgical kidney, it should properly be classified as one of direct infection at the first operation; for not only were the kidney and pelvis apparently normal when I first incised them, but on removing the ureter at the third operation, that tube was found to show neither dilatation nor gross pathological change. If we accept the current definitions of surgical kidney, this one could hardly be classified as such, since the definition implies the spread of suppuration from the bladder up the ureter into the kidney, and must of necessity call not only for evident ureteral dilatation and infection, but also for chronic changes in the kidney and pelvis. ${ }^{3}$

CASE 6.-This was one of wandering kidney in an histerical French woman, which I report because the condition was not recognized by me while the patient was on the table under an anesthetic, but was discovered by the house surgeon as she was erect and preparing to leave the hospital. The kidney could be brought close up to the anterior abdominal wall and had a decided pedicle. A nephrorrhaphy, after the usual methods, was performed, and although the kidney has been found in place by several surgeons, the patient claims to have sustained no relief from her symptoms.

CAse 7.-A case in which nephrotomy had been performed four months previously by another surgeon, with the successful removal of a stone of considerable size; a fistula persisted, and patient came under my care for relief. On exam. ination the entire secretion from the right kidney was found to be escaping through an opening, remaining at the lower extremity of a very long lumbar incision. An effort was made to close the opening by curettage, and by keeping the patient on the opposite side. This was unsucessful, and an opening was made embracing the lower half of the former incision, but extending to just above the middle of Poupart's ligament, as in Koenig's incision. The muscles being dissected back and the uninjured peritoneum stripped up, the ureter was disclosed from the brim of the pelvis to the point where it en. tered the pelvis of the kidney. No visible disturbance in the continuity of the ureter being noticed, a ureteral bougie was passed into the fistula in the hope of finding the ureteral orifice. The search was unsuccessful, except as it led to the discovery that the fistula passed directly through the lower pole of the kidney into the most dependent portion of the pelvis, and that gravity alone, without other assistance, would drain the bulk of the urine into the fistula. But this did not account for our inability to find the ureteral orifice, and a small incision was therefore made in the ureter about three inches below the kidney, through which the bougie was passed upward. On reaching the pelvis it would pass no further, and a careful inspection disclosed the fact that the scar from the original incision had passed through the lower portion of both kidney and pelvis, nearly bisecting the ureter. The contraction of the scar had evidently completely excluded the ureter. After some consideration it was decided to divide the stricture from without, cutting down on the point of the bougie by an incision parallel to the long axis of the ureter, and then to unite this incision-when it became evident that the ureteral orifice was again patent-transversely to the long axis of the tube after the Heinecke-Mickulicz method of pyloroplasty. This was accordingly done and the kougie, after closing the lower ureteral opening, was left in situ, the upper end projecting through the fistula. A drain was introduced down to the kidney and the wound was closed. No complication followed the operation, but on withdrawing the bougie, after five days, the urine refused to resume its flow through the original channel. The patient now passes the entire urine from that kidney through the fistulous tract. No nephrectomy was advised, because the urine from the opposite kidney contained some albumin and a few hyaline casts.

This case is instructive in showing that there is danger in too extensive incisions into the kidney substance and that in no case should the knife be carried so far through the lower pole of the organ as to encroach on the ureter. It is instructive also, in showing that the persistence of urinary fistulæ may be accounted for by gravity alone, since in this instance the fistulous opening from the pelvis must in the erect rosition have been considerably lower than that of the ureter. In such a case it was an absolute waste of time to try to close the urinary fistula. or to attempt to restore the patency of the strictured ureter by plastic operation. 
CASE 8.-Mrs. G., a tall, pale, neurotic, small-waisted woman of 46 , who boasted that she had been attended by twenty-four physicians prior to my own brief ministrations. She submitted to my examination, which was made at the request of her medical adviser, complacently, yet with frankly expressed doubt as to my ability to make a diagnosis, in which opinion I presently joined her. She gave a history of fairly normal pelvic organs, and the urinary examination was negative. Her digestion was impaired and her yellowish pallor showed deficient blood-production, though not sufficient jaundice existed to definitely associate the liver with her condition. There was constant slight pain or discomfort in the region of the ascend. ing colon, and palpation showed an indistinct body encroaching, as it seemed, from behind that structure. The patient stated that the enlargement was of recent date, as she had not noticed it until a year previously. On distending the colon it was found to lie in front of the growth, and the liver, apparently not enlarged, could not be shown to be either continuous with or separated from it. The tumor was fixed, did not seem to move with the slightly prolapsed liver, and could not be pushed into the kidney position. The flank was neither sunken nor swollen. This case has already been presented to a clinic as one of renal growth, that diagnosis having been based on exclusion of the liver, because the distended colon covered the lump. My own diagnosis was withheld because the tumor was indistinct, the other symptoms were obscure, the patient had not failed materially, and the colon relations alone were not sufficient to bring conviction that a prolapsed and adherent liver could be excluded. A preliminary examination under ether was proposed, but was refused by the attending physician on the ground that the patient was hardly strong enough to bear two anesthetics, so she passed on. An operation, performed at a clinic two weeks afterward, for removal of the tumor, disclosed a prolapsed corset liver with omental adhesions. The kidney was normal.

This case illustrates the fact that deductions based on colonic relations are not always to be depended on. The absence of urinary findings was in itself suspicious, though blood and kidney or tumor elements are not present in more than 60 per cent. of renal growths. Again, though the patient was ill-nourished, she was not cachectic and took life rather too easily for one afflicted with a growth of a malignant nature, such as this would probably have been had the kidney really been the offending organ. The case serves also to demonstrate that the elusive nature of the diagnosis of loin tumors should preclude anything like positive predictions as to their origin.

CASE 9.-This patient illustrates the same points and was brought by a suburban physician for the relief of gallstone colic. The patient was well nourished, with a color showing no trace of icterus; the doctor, however, stated that there had been jaundice, and severe colic located near the tip of the twelfth rib. An examination showed a rather movable tumor the size and shape of the kidney, behind the colon and near the edge of the quadratus Iumborum, apparently woo far back to be the gall-bladder. Urine analysis was negative. A cautious diagnosis of renal misplacement with possible tumor was made, but the incision was brought farther forward than usual, both because of the location of the swelling and in order to reach the liver in case of error. This course proved to be a wise one, for the tumor was a distended and prolapsed gallbladder with a very long duct, and contained mucus and calculi. Recovery was perfect.

This case was not mine, but I believed the kidney was the organ at fault, simply because it lay adjacent to the usual kidney location and felt very much like that organ. Of course, the negative urinary findings were ignored, as well as the small voice of the country doctor who was posted on jaundice, but had not read up on colonic relations. The case offered also an illustration of the practical working basis furnished by Lawson Tait's observation already quoted, that "the kidney" - or any other organ-" is best reached by the most likely-looking route."

CASE 10.-This case is introduced to demonstrate that the gall bladder may prolapse in front of, as well as behind the colon. The patient was brought to the city by her physician for an operation for appendicitis. When I saw her there was a not very tender tumor lying close to the abdominal wall, slightly above McBurney's point. Temperature and active symptoms had subsided, but the tumor continued. I made an incision without attempting a diagnosis, and found a prolapsed gall-bladder containing calculi and some pus mixed with mucus. There was recovery with a biliary fistula, taking a year to close.

Case 11.-T. C., aged 24, weight 110, family history tuberculous, and patient himself had had chronic cough and nightsweats for a year, with progressive emaciation. Right apex consolidated. A few days prior to admission to the hospital he was taken with colie, vomiting and constipation, and the right rectus abdominis became rigid. The abdomen was not distended and the temperature ranged a. m. 99, p. m. 101, with sweats at night. Pain was constant, but the vomiting and constipation disappeared shortly after admission. Urine analy. sis negative. There was no definite history of other attacks. Although the symptoms pointed strongly to appendicitis, the tendency of the pain to locate itself rather higher and more posteriorly and deeply than in appendicitis was thought worthy of consideration. Operation was withheld for thirty-six hours on account of these doubts, but there finally seemed no good reason to question the diagnosis of appendicitis. My house surgeon performed this operation, and was instructed to incise higher and more posteriorly than in an ordinary appendectomy incision. He was so cc.nvinced, however, that he was dealing with appendicitis that an incision was made over McBurney's point, which presently had to be extended four inches higher to reach a peri-nephrectic abscess containing several ounces of pus of tubercular origin. The appendix was not involved.

This case and Case 2 warn us that all abscesses covered by the ascending colon are not from the appendix. Taken with the preceding-Case 10-we note also the value of McBurney's point in establishing or excluding a diagnosis of appendicitis, for in Cases 2,10 , and 11 the spot of greatest tenderness was quite a little above that point. Pain radiating to or from the loin or liver is also of value in excluding appendicitis, for, though lumbar pain has occasionally been noticed, I doubt if in a great percentage of appendiceal disease the pain radiates in any other direction than toward the navel. We see here also that, other things being equal, the point of greatest tenderness is the point for incision, even when the diagnosis seems reasonably certain.

Cases 11 and 9 illustrate, respectively in a negative and positive way, the value of not allowing theoretic ideas to divert the surgeon's approach to the point of difficulty from a route manifestly in accordance with common sense, to one based on a preconceived theory of diagnosis.

CASE 12.-This was a man of 50, with a very large round tumor under the left ribs, extending downward into the loin and abdomen, and pushing the colon toward the median line. The progressive emaciation and cachexia pointed to trouble of a serious nature, but diagnosis was withheld until an ex. ploration was made through the abdomen. On reaching the growth it appeared to be the spleen. The wound was closed without proceeding farther and the patient presently went home no worse than before, taking treatment for splenic enlargement. After some months he returned for operative relief, requesting removal of the offending spleen, which was undertaken after advising him that his chances were small for recovery. An incision was again made across the peritoneum, and the tumor was found to be a carcinoma of the kidney which had attached itself to the spleen and had dragged 
that organ below its normal location. The kidney was removed.

This case did not occur in my practice, but it is so remarkable, and illustrates so perfectly the unusual distortion of normal relations which occur in renal tumors, that I add it to my list. Roberts describes a similar example of misplaced relations, the recollection of which led me into an error in locating the spleen in Case 14.

CASE 13.-E. C., aged 47 , traveling man, temperate, always healthy until February, when he commenced to emaciate and suffer with pain in right side near twelfth rib. In April a tumor which seemed to be the focus of the pain appeared behind the colon and at outer edge of quadratus lumborum muscle. In May he came under my care after having been in bed for several weeks. He was sallow but not jaundiced, had lost forty pounds; there was an evening temperature of 100.5 , no chills, no night sweats, no cough, bowels were open and tongue moist; the urine was loaded with urates, but contained no albumin, peptones, or organic elements; blood examination showed no increase of leucocytes. Spleen was not enlarged. The liver seemed to be enlarged upward, dulness reaching to within an inch of nipple and no lung sound below that line. The liver dulness extended higher posteriorly also, reaching to seventh interspace, and the lung sounds were not clear below that line. Change of position produced no change in the line of dulness, and an exploratory puncture withdrew no fluid. Below the liver and behind the colon a hard tumor had pushed itself into the flank between the twelfth rib and the iliac crest. It occupied a space about three inches in diameter, was irregular in outline, and seemed slightly movable, though not with respiration. It was not so tender but that it could be handled to test its mobility; it was continuous with the lower and posterior outline of the liver, but also lay on the quadratus in the kidney region. The temptation to make a diagnosis of malignant growth, with the patient's age and cachexia as a basis, was a strong one-in fact the patient had been told that he had a cancer of the kidneys. Granting malignancy, however, there seemed no good reason why the !iver might not have originated the growth from its dorsal border. But the lack of jaundice and indigestion, and the absence of blood and organic material in the urine, looked away somewhat from cancer of liver or kidney. The temperature, tenderness, and febrile urine pointed toward inflanmation, at least as a complicating factor in the problem; but the normal blood-finding and absence of peptonuria negatived the idea of an abscess. It would appear in this case that the diagnosis should lie between an inflameil malignant growth af either kichey or liver, and an intamed gall-bladder with omental adhesions possibly concealing an abscess. In the absence of convincing proof of the existence of any of these conditions the patient was informed frankly of the dilemma and advised to submit to an exploratory operation. He consented, and an incision parallel to the quadratus was made directly over the tumor. On reaching the deep fat, evidences of inflammation appeared, and on pushing forward the peritoneum to separate the tumor there was a gush of thick material riade up of fibrin, blood-clots and pus to the extent of eight cunces. On introducing several fingers into the sac the liver and peritoneum were found to lie anteriorly and the kidney and diaphragm posteriorly. The fluid continuing to flow after the sac was evacuated, the index finger traced the discharge to an opening beneath the ligamentum arcuatum externum of the diaphragm. Through this, access was had to the pleural cavity, and by the same route between one and two pints of the same thick fluid was presently evacuated. A microscopic examination of the material showed it to be made up of old blood, fihrin, unrecognizable shreds and a few pus-cells. Two drains were introduced, one into the abdominal sac, which had collapsed as soon as it was emptied, and another under the ligamentum arcuatum externum into the chest. The patient made a good recovery, although he hiccoughed a great deal, I think on account of the pressure of the tube passing through the diaphragm.

During his convalescence he stated that in January he fell from a chair on which he was standing to light the gas, and struck his side against the chair-back. He paid little attention to the injury, the pain disappeared in a few days and the circumstance passed out of his memory.

Cases 2 and 13 illustrate exquisitely the fact that many men of sturdy constitutions often sustain serious injuries which they presently forget in the stress of business and other activities; after a lapse of time disease appears, insidious in its course and mysterious in its manifestations, because the real cause has been put aside as inconsequent and forgotten. ${ }^{5}$ Such casesmost of them with a strong elementary foundation, I think, in passive inflammations occuring in slight and neglected traumas-usually prove enigmas, impossible jumbles without any correct key available prior to operation, but clear and consecutive enough when looked back upon as completed pictures.

CAsE 14.-Mary M., aged 24 months, very hearty and happy -in fact, a little over-nourished. There were no pathological changes in the urine, no hematuria, no pain in the side, even on freely handling a tumor which protruded noticeably into the left loin, apparently coming from behind and above. The lump was smooth but somewhat irregular, and proved on rectal insuffation of air to lie bchind but intimately associated with the colon. The latter structure seemed to run in a kind of groove on the tumor. The spleen was not to be made out in its normal location. The tumor could be shifted in all directions, though swinging from a central point near the normal location of the kidney. Manipulation was made the easier by a smaller lump, the size and shape of a small apple, which projected from the lower pole. The growth was an irregular sphere averaging about three inches in diameter, and we took it for a renal sarcoma which had contracted attach ments to the spleen, carrying the latter below and to the outside of its normal position. The colon was thought to lie in the groove, partially separating the two organs. In support of this view a case of cancer in a man aged 44, cited and diagramed by Roberts, was recalled, in which the spleen, usually pushed by renal growths well up under the diaphragm, was carried downward toward the iliac fossa in front of the mass.

It was decided to make an exploratory operation, to be followed by more radical measures should they seem to be justified. The loin was opened by an incision from the twelfth rib to one-half inch above the iliac crest and parallel to the outer border of the quadratus. This incision was afterward continued forward nearly to the rectus, dividing everything down to the peritoneum. That structure was not divided, but to. gether with the colon and much subperitoneal fat, was held back by sponges. On reaching the kidney the following observations were made: 1 . It was non-adherent to anything, being held merely by its own normal pedicle; 2 , the spleen was in its usual location and not in any way attached to the kidney; 3 , the small lump was the lower pole of the organ, and not yet involved in the tumor which had developed in the upper part of the capsule; 4, the growth had pushed the kidney over so that the pelvis lay in front and to the outside; 5 , the incision was ample for purposes of removal. Aceordingly, the mass was peeled away with the fingers from the peritoneum in front and the lumbar muscles behind, without encountering hemorrhage, adhesions or other difficulties, and by depressing the edges of the wound, it could be brought entirely out of the incision without traction, on the pedicle. Two long-bladed forceps clamped the pedicle, overlapping each other from above and below. The tumor was then removed and the pedicle tied with silk, the ends being left long and hanging from the wound. No especial effort was made to isolate the ureter from the vessels, and a small portion of the pelvis distal to the ligature was left in the wound. I could find no glandular metastasis. Astonishingly little hemorrhage taking place, the cavity was packed and drainel, and the extensive muscle and skin incision was brought together by catgut and silkworm sutures. There were no complications except a temperature 
developing on the third day after removing the drainage tube; on returning the tube the temperature fell, about an ounce of thin purulent fluid escaping which had probably been infected from the stump of the ureter. Eight weeks after the opera. tion the silk ligatures came away and the wound closed immediately thereafter. The patient is in excellent health and shows neither cachexia nor emaciation; the abdomen is larger than it was prior to the operation the bowel appearing to have lost some of its tonic contraction, but a tight binder is reducing the protrusion. The kidney and tumor weighed about eighteen ounces, and a report of the pathological examination made by Mr. Ready, of St. Luke's Hospital is appended.

Six months after the nephrectomy, this patient was brought back to me with a recurrence of the growth at the site of the original operation. The recurrent tumor is considerably larger than the original growth, and so diffuse as to be inoperable. She is now under treatment with mixed toxins.

In analyzing this case several points of interest are developed: 1, the diagnosis of organs involved and the kind of tumor; 2, elements entering into the choice of operation; 3, What were the errors in the operative technique?

A tumor appearing in the left loin of a fat and healthy child of 2 years could hardly be anything but a sarcoma-syphilis of the spleen, tabes mesenterica, retained feces, or congenital cysts, need hardly be considered. Hydronephrosis rarely produces a lobed tumor, nor did the growth fluctuate in size. The absence of history of traume, as well as the age of the child, pointed toward a congenital growth. So, also, its painless and non-inflammatory development-without adhesions -occurred almost as smoothly and quietly as in the normal evolution of a normal organ. That the kidney should have turned halfway round on its long axis, between the peritoneum and the loin muscles, and neither have contracted adhesions nor have produced trouble through traction on the vessels, etc., in the pedicle, is certainly a remarkable evidence of the plastic character of infantile structures. The fact that this tumor is within its own capsule as well as within that of the kidney, and that the kidney tissue around and below it was still healthy and evidently performing its function, points toward the retention of fetal, but unhomologous elements within the kidney stroma as the starting point of the growth. I am disposed to regard it therefore as arising from the pronephros as described by Grawitz and Klebs, ${ }^{8}$ although Mr. Ready describes it as an adenosarcoma, without referring to its origin. A curious fact is noted by König that these sarcomas are much commoner in girls than in boys. As to a diagnosis of the organs involved, this also appeared easy, for the tumor had not yet attained sufficient size to push the colon toward the median line, and away from its normal relations to the kidney. To call the smaller lump the spleen, however, was hardly excusable, for a moment's thought would have shown, that so freely movable and uninflamed a growth could never have contracted adhesions to the spleen sufficient to drag it halfway down the abdominal cavity and around the splenic flexure of the colon. Such dislocations of the spleen are rare and, as in Case 12, and in Roberts' case, cited above, occur only in older persons with carcinoma of growth slow enough to produce intercurrent inflammations with resulting adhesions.

The comparatively small size of the tumor and its early recognition afforded ample justification for its removal. This growth weighed about one pound. Königig has removed some of enormous size, weighing up to ten pounds, without immediate death. Nevertheless, the immediate mortality in nephrectomy for tumor is appallingly high, both König and J. W. White quoting Sigrist's statistics of 64 operations with 32 deaths attributable to the operation alone. Of these 64 patients only 5 were alive at the end of two years, and but one of Kronlein's series of 5 cases lived four years in good health.

As to the choice of operations, I believe the lumbar route by Konig's' ${ }^{11}$ long-curved incision, with the operation field lying entirely outside of the peritoneum, was the best in this case. Jacobson ${ }^{12}$ also prefers this incision where tumors are of moderate size and without dense adhesions. ${ }^{13} \mathrm{He}$ concludes that the König incision is the one of election in all those cases where the peritoneum can be pushed to one side and the tumor is not too large for a loin incision. As showing the statistica] argument for and against both methods, König ${ }^{14}$ gives the following for what they are worth : $:^{15}$ Immediate death after transperitoneal incisions 58 per cent.; immediate death after extraperitoneal incisions 24 per cent.; recorded recurrence among survivors of transperitoneal incisions 5 per cent.; recorded recurrence among survivors of extraperitoneal incisions 41 per cent. König, therefore, thinks it an error in the interest of radical work not at least to consider the transperitoneal route. $J$. W. White, also, thinks that with large tumors and more modern asepsis the transperitoneal operation is slowly gaining ground. ${ }^{16}$

Let us now seek, briefly, to summarize the errors with which the foregoing fourteen cases appear to have been fraught. Roughly classified, the miscarriages appear to have resulted from a violation of one or more of the following principles:

1. The surgeon should not attach too great weight to the recollections or the subjective symptoms of the patient, unless borne out by the physical signs. Thus the tale told by the patient with corset liver -Case 8-. that her "tumor" appeared during the previous year must have been a fabrication, though she herself may also have believed it. In like manner the ill-starred schoolmaster went to his fate because his surgeon, in the absence of objective manifestations, did not cultivate a wise and conservative skepticism of the patient's ability to make his own diagnosis.

2. On the other hand, due weight should be given to statements made by intelligent patients, especially in cases where the objective testimony is abundant, but confusingly contradictory. Every legitimate opportunity should be offered the patient to establish a sequence of disease. Careless history-taking is responsible for more than a little obliquity of diagnosis. Thus, in the gathering and arrangement of minute and seemingly inconsequential facts, the two cases of traumatic abscess (2 and 13) might have been spared a good deal of perilous delay, and the surgeon a good deal of humiliating mystification, had the relations between trauma and tumor been sufficiently indicated in the history.

3. It is an error in patnologic conditions to place too great reliance on relations normal to the healthy individual. It is probable that exaggerated stress has recently been laid especially on certain normal relations of the colon, and that nunierous absolute and exclusive diagnoses have been based on supposed correlations between tumor and colon, which were hardly borne out by subsequent operative revelations. (See Cases 8 and 9.) No diagnosis of tumor or structure is complete until consideration has been given to the possibility of the encroachment by organs or growths on the normal 
sites of organs which prima facie evidence would lead us to believe to be the ones involved. In this connection, it is interesting to observe how easy it is to regard as pathognomonic certain signs happening to be much discussed in current literature (Case 8), and also how easy it is to think two cases identical because they happen to bear a certain superficial resemblance (Case 14).

4. It is an error, even in the presence of conditions which seem pathognomonic, to neglect every diagnostic resource, and to follow up each resource faithfully to its logical conclusion. Thus, in Case 2 , the blood and pus in the urine, and the valuable deductions to be made therefrom, were ignored; in Case 3 the urine was probably not filtered, and a diagnosis of Bright's disease was made on the mere existence of albuminuria; in the same case, although a skiagraph was taken, the plate was so placed as to fail in taking the entire urinary tract, and a stone was, probably on that account, overlooked. In Case 5 a skiagraph was entirely omitted and no stone was found. It is difficult, at the present time, to justify a nephrotomy, undertaken for the avowed purpose of removing a calculus, where a preliminary skiagraph has not been prepared. Although it is contended that pure uric-acid calculi fail to give a shadow, this is hardly at present a matter of sufficient demonstration to warrant such an omission in every case of suspected calculus. The negative testimony afforded by the absence of shadow may lead to a revision of diagnosis and treatment not particularly productive of glory to the operator, but often of incalculable benefit to the patient.

In this connection it may be well said that no class of cases more than these calls for such careful and persistent observation of the physical signs, and the hourly record of temperature, urine, etc. Thus, in Cases 5 and 14 the temperature chart revealed abscesses, which might have proved fatal in the absence of the record and deductions based thereon. In Case 13 a more careful working-out of the physical signs might have pointed even prior to the operation to a subphrenic abscess.

5. Among operative errors, may be noted the failure to properly care for the ureter in Cases 5 and 14 . The ureter should be ligated with catgut and brought separately into the wound after cauterizing with carbolic acid; or, better still, should be inverted a short distance and stitched. Kidney stumps should not be ligated with silk (Case 14). Too deep incisions into the kidney structures are dangerous and jeopardize the subsequent integrity of the pelvis and ureter (Case 7). The kidney and the operation wound should not be closed primarily after nephrotomies. Drainage for a few days, at least, is much safer and may save a subsequent nephrectomy. (Case 5.) A kidney which is riddled with sinuses is best removed; conservative measures only lead to another operation. (Case 2.) It is an error to base an incision on any preconceived idea of diagnosis. Rather follow Tait's rule that "the kidney is best reached by the most likely-looking route." (Cases $9,10,11$ and 13.)

NOTES AND REFERENCES.

1. Jacobson: Operations of Surgery, 3d ed., p. 714

2. Loc cit.. pp. 715-716.

3. Chicago Medical Recorder, 1899. Also Century Dictionary: "Surgical Kidney is a term somewhat loosely applied to chronic nephritic conditions arising from trouble farther down in the urinary tract, but especially to pyonephrosis arising from a cystitis."

4. Roberts: Urinary and Renal Diseases, 4th ed., p. 525.

5. An interesting consideration of this class of cases is found in Paget's Studies from Old Case Books under the title "Obscure Cases of Caries of the Spine." He calls them "quiet diseases." G. Roherts: Eoc. cit.
7. Extirpated kidney, weighing $121 / 2$ oz, measuring $4 \times 31 / 2 \times 3 x$ $21 / 2$ inches. Macroscopical examination: Both poles and a por. tion near the hylus show normal kidney substance; the remainder is occupied by a bulging tumor mass; near the lower pole the tumor extends $21 / 2$ inches above the niveau of the external surface. Section shows a soft growth measuring $31 / 2 \times 3 \times 2$ inches, extending from the capsule of the kidney (near the lower pole), and bulging into the pelvis. The tumor shows in places a tense fibrous capsule, from which it can be separated with some difficulty. The portion projecting above the niveau of the kidney is covered only by kidney capsule. Microscopical examination: Sections show epithelial cells traversed by bands of connective tissue, and without any characteristic arrangement. There are also large masses of cuboidal epithelial cells in groups of tubules, especially well marked in sections taken from the center of the growth. Near the periphery these neoplastic acini and tubules almost disappear. The tumor is quite vascular and hemorrhagic. Diagnosis: Adenosarcoma.

8. König: Spec. Chir., ii, 635.

9. Loc. cit., p. 636 .

10. Loc. cit.. p. 636

11. Loc. cit.. p. 654 .

12. Jacobson: p. 753 .

13. In this view he is opposed by $K$. Thornton, and an interesting analysis of the arguments for and against the intraperitonea and extraperitoneal approaches to the kidney and its tumors found on pages 737 and 764 loc. cit.

14. König: p. 638 .

15. These statistics are fundamentally deceptive and König himself warns against basing any deductions on them. The reason is quite obvious.

16. Dennis : Syst. of Surg., iil, p. 475.

DISCUSSION

Dr. J. E. Owens-I have but little to say about this valuable paper. It reminds me, however, that long since diagnosis was defined to be the "science of probabilities." The cases reported are certainiy very interesting and instructive. The paper, being a report of a series of cases in which errors are more or less mingled, is more useful than a report of a series of suceesses. I have always thought a carefully-prepared paper on deaths after operations well worthy of the consideration of any society, particularly of a surgical society; and likewise a paper on errors of diagnosis and unexpected aberrations encountered in operative surgery. But how rarely are such paper's presented. It is very natural for us, even the older members of the profession, to report successes, leaving the less fortunate cases as silent teachers for ourselves. It will stinulate us to be more fearless in relating some of the complicated problems met with in practice.

I have failed with the needle to find stone. No further operative steps were taken in these cases as a promise was exacted beforehand, that if we did not find a stone we should not operate. Many times since the period $I$ am about to speak of, I have asked patients "Were you drunk?" This was suggested to me by one of my cases. A saloon-keeper sent for me one night on account of a severe sticking, or lancinating pain in his side. He said he had not been hurt, and that he knew of no reason for his trouble. I put my ear to his chest and discovered a friction sound, so I said, "Put a blister upon the part complained of and I shall call again." Two days later the patient said, "You are not in it. I had the pain so badly I sent for another doc. tor and he fumbled about my chest and found a broken rib." "How did you get a broken rib, as you said you were not injured?" "I will tell you; I was very drunk and the folks told me a man said he could throw me, and he did."

Loin pain in appendicitis is often very severe. I had an attack of appendicitis some years ago and experienced intense pain far back in the loin, as well as in the appendiceal region. Other such cases have come to my notice. The use of silk in such operations is not desirable. It will almost certainly come out or give trouble sooner or later. I have had it do so in nephrectomies, and in other operations. I remember well an operation for a large venous varix extending from the armpit to the crest of the ilium. Seventy-five to one hundred silk ligatures were employed. During the following five or six months many of them came away or had to be removed.

Dr. D. A. K. STEere-I quite concur in the suggestion of the President that if we could have a society of surgical and medical pessimists it twould be a good thing. I believe there is such a body in London, where no fellow is allowed to report his successful cases. only his failures. We might once in a year or two have such a meeting with profit. 
Some of these cases remind me of a personal experience along the same lines where a subdiaphragmatic right abscess was overlooked and mistaken for disease of the kidney. Two such have fallen uncer my observation. In neither was there a history of preceding injury, although undoubtedly an injury may have been precedent. The question whether the patient had been intoxicated was not asked. One of these cases was in the service of another physician and I was present at the operation. The kidney was incised under the impression that it contained a stone. It was explored with a needle and unnecessarily handled, and just before the kidney was closed up the abscess was accidentally discovered and drained, but the patient did not recover.

One of the cases reported by Dr. Allport, No. 12, seemed to me incomplete, because he did not tell us what became of the patient. A case of interest in this connection came under my observation three years ago, a colored man, 56 years of age, who had been under the care of Dr. Quine for some weeks for persistent pain in the region of the right kidney. He examined him, treated him for some weeks and made a diagnosis of stone in the kidney. I saw the case in consultation, and he was subsequently placed under my care at Wesley Hospital with the request that I operate. I do not know why, but I had an idea there was some mistake in the diagnosis; the operation was fixed for two different days and postponed by me on account of doubt as to the propriety of operating, and then I asked Dr. Danforth to see the case. He said the symptoms pointed to stone in the kidney and it was a case for operation. This was Saturday, and I said we will operate Monday. I called to see the patient Sunday; he had eaten a hearty dinner and was laughing and joking, when he suddenly complained of feeling faint, said, "I cannot see anything" and fell back on the bed; in ten minutes he was dead. I made the post-mortem examination and found that he had a ruptured aneurysm that was overlooked. Fortunately for me I postponed the operation until nature ended his life; had I operated we would have had a death on the table. The kidney was normal, but displaced by the aneurysm behind it; there was only a quart of blood behind the kidney. It was an an. eurysm of the renal artery. There is another class of eases, two of which I have under observation now, and have had during the past year, in which there are classical symptoms of stone in the kidney, in which I have declined to operate because the skiagraph fails to show the presence of the kidney stone. For the last year I have availed myself of this aid to science in diagnosing stones, and not finding them in the skiagraph $I$ decline to make a positive diagnosis.

Dr. L. L. McArthur-In the series of cases reported by Dr. Allport, reference is made to the appearance of a few bloodcorpuscles and pus-corpuscles in the urine, and yet the case was suspected to be appendicitic. Although there has not yet been any paper written calling attention to this fact, it is nevertheless a fact that blood-corpuscles in quite liberal number, and even albumin accompanying them sufficient to give a nitric-acid reaction, will be present in a certain small percentage of cases of appendicitis. I have had four cases in which it was difficult to decide whether it was renal colic or appendicular colie, and still more difficult after a microscopic examination and finding blood. In two cases in which the temperature seemed to be out of all proportion for renal colic, operation was had and gangrenous appendicitis was found, although bloody urine, vesical tenesmus, and albumin were found in the urine, and those symptoms which go with renal colic were present.

As to skiagraphs of stone in the kidney, I presented a paper before the Chicago Medical Society with skiagraphs of all varieties of renal stones, and at that time called attention to the fact that we must not look for $a$ distinct shadow from renal calculi of organic origin. For instance, uric-acid calculi are probably the most frequent of all calculi, amounting to nearly 89 per cent. Uric-acid stones cast almost no shadow on the plate itself and how much less when it is to be observed through the body.

I returned to the city this evening rrom a case to which I was called at Columbus, Wis., that had been under the obser- vation of three doctors for three years-a woman 58 years of age. the mother of a large family, who for three years has been complaining of obscure pains in the right loin. She had some yellowness of the skin and presented a tumor movable in respiration in the right loin in the neighborhood of the kidney. I was calied to see the case because it was supposed to be a tumor of the kidney. Uranalysis was negative. On examining the case this morning a tumor was very distinctly to be palpated, which moved with respiration, and by bimanual palpa tion moved backward and forward as well as up and down, but the colon had not been inflated. So I inflated that and found the tumor lying anterior to the colon. That, taken with the fact that the colon was very distinctly palpable and the patient was icteric, led me to believe that it was a tumor of the liver or distension of the gall-bladder. I made a diagnosis of tumor of the liver, probably ecchinoccocus and not malignant, because the patient had not emaciated. An exploratory incision was advised and enlargement of the incision to remove the trouble if found feasible. A small incision was made to the outer margin of the rectus and a corset liver found, a lobular elongation shaped like the kidney. The kidney was perfect, distinctly palpable behind it, of infantile size, nothing in the pelvis and the gall-bladder very small. Nothing was to be found in the neighborhood of the ileum, or pancreas. Such mistakes can be made as Dr. Allport describes in his paper without any reflection being cast on the surgeon. At one of the meetings of the British Medical Society, for a presidential address, Paget read a paper entitled "Necessary Errors in Diagmosis." A logical conclusion can not but be drawn from the premises furnished, sometimes the premises are false and therefore your conclusions false. Jacobson says, any opera. tion which justifies exposing the kidney for handling also justifies the exploration of that kidney with the finger. I think it extremely difficult, even with the finger, to find a stone; I know they are overlooked, I have done it myself; how much more difficult is it with the needle! I chanced to be present at the operation on the 14th ease reported by $\mathrm{Dr}$ Allport, and as he was about to amputate his ligatures I suggested that he leave one long so as to extend out of the wound. I think that extremely wise, because they do suppurate frequently. If you have an end, you can take hold of it and yon can get them out by a small amount of continuous elastic traction.

Dr. D. N. Eisendrath-Case No. 1 seemed to come under the class of hysterical pains which are so frequently met in viscera, the stomach, spleen and kidney; they come under the head, in this case, of nephralgias. The second case was one of hematuria, without apparent cause until afterward trauma was found. I was interested because there are so many cases of hematuria without apparent cause which are due to tuberculosis. I read a report of a case in a German journal of very severe hematuria coming on suddenly in a patient without tubercular history, but operation showed typical tuberculosis of the kidney.

The case on which I did nephrectomy during the absence of Dr. McArthur from the city, in 1898, was undoubtedly a surgical kidney; it was an ascending pyelonephritis, and was hardly of the variety in which infection could have taken place except from the bladder upward. It is not likely that infection at the time of operation would have caused this form of infection of the kidney, which most frequently ascends from the bladder, passing upward through the ureter. Weir reports four cases in which surgical kidney was strictly unilateral, so I think the infection came from the bladder, and not from the previous operation.

Painful Limping from Uteropathy.-De Luca writes to the Riforma Medica of February 7 , deseribing three cases of lameness in women, owing to severe pains that appeared at the first steps or after walking a certain length of time. The pains affected the various groups of muscles in the lower mem bers, and disappeared when the patient sat or reclined. The hobbling gait was traced to the influence of displacement of the uterus, retroversion. lateroversion or prolapse with anteroversion. Alexander's operation in one case cured the limping and pains at once. In the others there was no operation performed. 